\title{
Review \\ The Role of Artificial Intelligence in the Diagnosis and Prognosis of Renal Cell Tumors
}

\author{
Matteo Giulietti ${ }^{1}$, Monia Cecati ${ }^{1}$, Berina Sabanovic ${ }^{1}$, Andrea Scirè ${ }^{2}{ }^{\circ}$, Alessia Cimadamore ${ }^{3}\left(\mathbb{D}\right.$, Matteo Santoni ${ }^{4}$, \\ Rodolfo Montironi ${ }^{3}$ and Francesco Piva ${ }^{1, *}$ \\ 1 Department of Specialistic Clinical \& Odontostomatological Sciences, Polytechnic University of Marche, \\ 60126 Ancona, Italy; m.giulietti@univpm.it (M.G.); m.cecati@univpm.it (M.C.); \\ b.sabanovic@pm.univpm.it (B.S.) \\ 2 Department of Life and Environmental Sciences, Polytechnic University of Marche, 60126 Ancona, Italy; \\ a.a.scire@univpm.it \\ 3 Section of Pathological Anatomy, Polytechnic University of Marche, United Hospitals, 60126 Ancona, Italy; \\ a.cimadamore@staff.univpm.it (A.C.); r.montironi@staff.univpm.it (R.M.) \\ 4 Oncology Unit, Macerata Hospital, 62012 Macerata, Italy; mattymo@alice.it \\ * Correspondence: f.piva@univpm.it
}

Citation: Giulietti, M.; Cecati, M.; Sabanovic, B.; Scirè, A.; Cimadamore, A.; Santoni, M.; Montironi, R.; Piva, F. The Role of Artificial Intelligence in the Diagnosis and Prognosis of Renal Cell Tumors. Diagnostics 2021, 11, 206. https://doi.org/10.3390/diagnostics 11020206

Academic Editor: Carlos Maria Galmarini

Received: 21 December 2020

Accepted: 26 January 2021

Published: 30 January 2021

Publisher's Note: MDPI stays neutral with regard to jurisdictional claims in published maps and institutional affiliations.

Copyright: (c) 2021 by the authors. Licensee MDPI, Basel, Switzerland. This article is an open access article distributed under the terms and conditions of the Creative Commons Attribution (CC BY) license (https:// creativecommons.org/licenses/by/ $4.0 /)$.
Abstract: The increasing availability of molecular data provided by next-generation sequencing (NGS) techniques is allowing improvement in the possibilities of diagnosis and prognosis in renal cancer. Reliable and accurate predictors based on selected gene panels are urgently needed for better stratification of renal cell carcinoma (RCC) patients in order to define a personalized treatment plan. Artificial intelligence (AI) algorithms are currently in development for this purpose. Here, we reviewed studies that developed predictors based on AI algorithms for diagnosis and prognosis in renal cancer and we compared them with non-AI-based predictors. Comparing study results, it emerges that the AI prediction performance is good and slightly better than non-AI-based ones. However, there have been only minor improvements in AI predictors in terms of accuracy and the area under the receiver operating curve (AUC) over the last decade and the number of genes used had little influence on these indices. Furthermore, we highlight that different studies having the same goal obtain similar performance despite the fact they use different discriminating genes. This is surprising because genes related to the diagnosis or prognosis are expected to be tumor-specific and independent of selection methods and algorithms. The performance of these predictors will be better with the improvement in the learning methods, as the number of cases increases and by using different types of input data (e.g., non-coding RNAs, proteomic and metabolic). This will allow for more precise identification, classification and staging of cancerous lesions which will be less affected by interpathologist variability.

Keywords: renal cancer; machine learning; artificial neural networks; support vector machines; random forests; NGS

\section{Introduction}

Renal cell carcinoma (RCC) is not a single entity but rather a heterogeneous set of tumors classified in about 40 subtypes, of which clear cell (ccRCC), papillary and chromophobe RCC account for 70\%, 10-15\% and 5\%, respectively [1]. ccRCC is usually asymptomatic in the early stages, and about $25-30 \%$ of patients present metastasis at the time of diagnosis. Detecting ccRCC in the early stage would significantly ameliorate the prognosis, even though localized ccRCC removal by nephrectomy does not eliminate the high risk of metastatic relapse [1,2]. Therefore, also considering the increase in the number of RCC cases, development of efficient strategies for an early diagnosis and for the identification of tumors with a worse prognosis is very important.

In fact, tumor staging is not only a valuable prognostic factor, but it is also used to determine the right treatment strategy for patients and to predict the risk of metastasis 
development. The currently adopted prognostic factors for RCC include the TNM staging system, the four-tiered WHO/ISUP (International Society of Urological Pathology) grading system, histologic subtype, presence of the sarcomatoid component, microvascular invasion, tumor necrosis and invasion of the collecting system [3]. In case of the metastatic RCC, the most effective prognostic factors are the histological subtype and the presence of the sarcomatoid component [4]. Nomograms, models based on different prognostic factors that affect survival, have been developed to improve the prediction of patient outcomes [5-7]. Among these factors, or variables, we mention sex, race, marital status, smoking history, type 2 diabetes mellitus, age at diagnosis, $\mathrm{T}$ stage, $\mathrm{N}$ stage, $\mathrm{M}$ stage, Fuhrman nuclear grade and surgical approach.

At the same time, the use of molecular data has been explored to improve the reliability of diagnosis and prognosis in RCC. Currently, next-generation sequencing (NGS) techniques offer the opportunity to extract a multitude of new features, genomic and transcriptomic, potentially related to the phenotype. For example, gene variations, RNA expression, alternative RNA splicing events and gene fusions data from a biopsy are relatively easily obtainable [8]. However, the procedures for identification which, of the many possible variables, are indeed related to the diagnosis and/or prognosis are challenging. Thanks to bioinformatic and statistical methods, it is possible to reduce the number of variables, for example, by identifying gene groups with a correlated expression and selecting a representative gene for each group [9]. Application of these filters results in a reduced number of variables suitable for analysis by typical algorithms of machine learning. Artificial intelligence algorithms can learn the relationships among data, even if they are non-linear relationships. A simple example would be a case in which the expression of five genes is related to the diagnosis of cancer, but it is unknown what weight to attribute to each gene and what formula links the gene expression to the diagnosis. By analyzing many cases, artificial intelligence algorithms would be able to learn the relationship that links the input variables (sociological, clinical, molecular) to an output variable, such as diagnosis or prognosis or the response to treatments $[10,11]$. In other words, these algorithms act as classifiers that, by integrating molecular information from medical big data, will allow for the selection of specific treatments, thus making a "precision medicine".

\section{Machine Learning Algorithms}

In this section, the main algorithms used to implement diagnostic and prognostic predictors starting from molecular variables in RCC will be summarized. However, extensive and recent reviews of the history of AI and its applications in medicine and oncology were carried out by Hamamoto et al. [12] and Hamet et al. [13]. More specific applications in urologic oncology have been carried out [14], including those based on radiological images for diagnostic and prognostic purposes in RCC [15] or those for prediction of RCC incidence over time [16,17].

Machine learning, the algorithms to implement AI, can be divided into two main types: supervised and unsupervised learning [18]. The former method is used for extracting features from input data to make predictions and address the classification and regression tasks. The classification problem is used to map input to output labels, that is, to predict discrete data, for example, distinguishing between healthy and sick. The regression problem is used to map an input to a continuous output, that is, to predict survival [19]. Unsupervised learning learns the inherent structure of data without labels being provided and the most common task is clustering. It should be noted that since no labels are used, in most cases, there is no specific way to assess model performance. Some of these algorithms include k-means clustering and principal component analysis [20]. The studies that will be examined in the next section adopted supervised learning, so now we will mention these algorithms.

The best-known artificial intelligence algorithms are artificial neural networks (ANNs), structures that mimic the neuronal topology of the human brain. They can have several artificial neurons (or nodes) organized in layers, and neurons of each layer can implement 
different transfer functions. All of this ensures a great flexibility in dealing with different tasks. Generally, the available cases are divided into a training set and a test set (for example, in a 70:30 ratio) but sometimes into training, validation and test sets (for example, in a 70:15:15 ratio). These algorithms perform well if the training data are numerous, representative of reality and not contradictory. Many training attempts must be made before the desired performance is achieved, and during these attempts, it may be necessary to modify the network structure, i.e., number of nodes and the type of transfer function.

While an advantage of ANNs is their ability to discover and model complex relationships among data, they present two weaknesses. Firstly, since ANNs are non-linear algorithms, training usually results in a relative minimum of the error function (between obtained and expected outputs) and not in the absolute minimum. The second is the overfitting of the data, which is a condition that occurs when the algorithm does not generalize the data profile but tries to follow them so precisely that it ends up chasing noise. Fortunately, this drawback can be easily noticed; in fact, too high performance on training data and very poor performance on test data indicate overfitting. Overfitting can also be prevented by applying methods that interrupt the learning cycles of the algorithm when the performance of the two datasets (training and test) starts to diverge [21].

Support vector machines (SVM) are also algorithms used for classification. During the learning process, these algorithms look for a hyperplane separating the two datasets (for example, healthy from sick or short from long survival). SVMs do not use all the data for the learning but rather only one datum representing the closest point between the two sets (called support vectors). Usually, these algorithms are linear; therefore, they reach the absolute minimum of the error function. Moreover, they are particularly suitable when there is a clear separation between the data groups to be classified. Instead, they have poor performance in the case of noisy data [22].

The random forests algorithm (RFs) combines the predictions of many decision trees (forests) into a single model. Each decision tree learns from a subset of elements chosen randomly from all available training data (bootstrap). Subsequently, the average of the predictions of each decision tree (bagging) is calculated, allowing obtaining the final predictions [23].

Finally, Lasso regression (least absolute shrinkage and selection operator regression) is an algorithm that performs independent variable selection (feature selection) and regularization (to reduce variance). It can select important predictors of a model [24,25].

However, there are several challenges in the application of machine learning to large amounts of data, such as genomic data. The first problem, which we have already mentioned, concerns data overfitting that occurs because the dimension of the input is much larger, at least one order of magnitude, than the sample number, and this is also known as the "large $\mathrm{p}$, small $\mathrm{n}$ problem". Second, the influence of each input variable on the prediction is difficult to assess because of the multiple non-linear operations. The third problem is called the "black box problem", that is, it is not possible to understand the reason that generates the results and to predict the behavior of the system due to the complexity of the machine learning techniques. Since the European Union's General Data Protection Regulation (GDPR) of 2018 requires the transparency of AI, it will be necessary to address the black box issue [26].

\section{Artificial Intelligence-Based Predictors in RCC}

In this review, we investigated and reported the state of art of the application of AI for diagnosis and prognosis in renal cancer using only molecular data as input, the most commonly selected genes, and we analyzed the non-AI-based predictors making a comparison between the two approaches. A Pubmed search was conducted using the keywords "artificial intelligence", "machine learning algorithm", "renal cell carcinoma", "renal cancer", "kidney cancer" and excluding the keywords "radiomic", "imaging", "histopathology images", "CT-based", "tomography" and "MRI". 
Most of published studies are focused on the prediction of prognosis and diagnosis in clear cell RCC since this is the most dominant type of renal cancer; therefore, more data are available and, consequently, the algorithms can be better trained. Only two publications, of the same authors, concern predictions on the papillary cancer type $[27,28]$.

Usually, the RNA-seq gene expression and, in some cases, methylation data were obtained from The Cancer Genome Atlas (TGCA) resource, thus ensuring the uniformity of the starting data. Various authors used level 3 TGCA data [27,29,30], i.e., already aligned to the reference genome and quantified, but we must consider that also these processed data are dependent on the algorithm and its parameters [31]. In other papers, the transcript quantification was calculated by RSEM software [32,33].

The first phase of the analyses consists in identifying the most differentially expressed genes (DEGs) between the control and treated condition. This objective is not trivial; in fact, there are still limitations and biases that do not allow capturing all the DEGs due to the preparation of the library, the different representativeness as a function of the RNA length, the alignment of the reads and the tests for expression [34-37]. For the identification of DEGs, edgeR [38,39] and DEseq2 [40] R packages were used. Instead, differential methylation was calculated by $\mathrm{R}$ package limma [40] or the minfi package tool [28]. A downside in applying these methods lies in the assumption that there is no potential correlation between groups of genes. However, in biological reality, there may be gene-gene interactions that play a key role in specific conditions, whereby groups of genes could show an effect as a group, but not as single genes [41].

The second phase of the analyses consists in a reduction in the starting data (feature selection) to only the most important ones for discriminating cases, and this represents a challenge. In several studies, the feature selection was obtained through various methods, for example, using clustering algorithms, principal component analysis or random forests. In particular, as selection criteria, we start from simple methods, statistical P-values and fold changes [38]. More elaborate methods are another option, such as the "SymmetricalUncertAttributeSetEval" (of the Waikato Environment for Knowledge Analysis) and the "Fast Correlation Based Feature" algorithm [29,30], and these methods are based on performance in terms of discriminatory power (ROC) or on an SVM model [30]. It is also worth mentioning the minimum redundancy maximum relevance method [42], feature selection by the "Fast Correlation Based Feature" algorithm or joint statistical measures and logistic regression [32]. Finally, Ping et al. used the random forests algorithm for variable selection, after calculating the adjusted false discovery rate [33]. Similarly, the shrunken centroids and random forests (varSelRF) methods [27,28] and Lasso regression [39,40] were used for selecting features for predictors.

Table 1 shows a summary of the studies that used machine learning techniques for RCC diagnosis and prognosis prediction. In a study from 2014, the authors tried to discriminate ccRCC clinical tumor stages (early stages (I, II) and late stages (III, IV)) employing four different supervised machine learning algorithms (J48, naïve Bayes, sequential minimal optimization and random forest). The initial 20,534 genes from TCGA (The Cancer Genome Atlas) were reduced to 62 and their expression in 475 tumor samples was used for algorithm training [29]. The random forest based classifier reached the best performance, that is, $88.89 \%$ sensitivity, $76.84 \%$ accuracy and an auROC of 0.778 .

Furthermore, in order to distinguish cancer from non-cancer samples, RNA-seq data of 537 ccRCC patients collected in TCGA were used to train a supervised learning classifier based on a support vector machine (linear kernel), and the receiver operating characteristic (ROC) curve was adopted to measure the performance of this classifier [38]. The algorithm performance seems very good, as seen from the values of sensitivity of $96.5 \%$, specificity of $97 \%$ and the area under the receiver operating curve (AUC) of $98.7 \%$, but unfortunately, they are referred to overall performance (training and test set). Instead, it would be interesting to evaluate the performance on test sets alone. Moreover, another weakness is that 186 genes were used, and it would be interesting to reduce the number of variables for classification. 
Table 1. The table collects the studies that used machine learning techniques to predict diagnosis and prognosis.

\begin{tabular}{|c|c|c|c|}
\hline Aim & Technique and Data & Results & Reference \\
\hline ccRCC stages (I and II vs. III and IV) & $\begin{array}{l}\text { J48, naïve Bayes, sequential } \\
\text { minimal optimization and } \\
\text { random forest on RNA-seq data } \\
\text { from TCGA }\end{array}$ & $\begin{array}{l}62 \text { genes selected. Random forest was } \\
\text { the best predictor: } 88.89 \% \text { sensitivity, } \\
76.84 \% \text { accuracy and auROC of } 0.778\end{array}$ & Jagga et al., 2014 [29] \\
\hline ccRCC vs. normal & $\begin{array}{l}\text { SVM on RNA-seq data } \\
\text { from TCGA }\end{array}$ & $\begin{array}{l}186 \text { selected genes, overall sensitivity } \\
\text { 96.5\%; overall specificity } 97 \% \text {; overall } \\
\text { AUC } 98.7 \%\end{array}$ & Yang et al., 2014 [38] \\
\hline ccRCC survival (< or $\geq 5$ years) & $\begin{array}{l}\text { SVM and KNN learning on } \\
\text { RNA-seq data from TCGA }\end{array}$ & $\begin{array}{l}\text { SVM (AUC 0.6042; total accuracy } \\
0.6111 \text { ) KNN (AUC 0.6444; total } \\
\text { accuracy 0.6481) }\end{array}$ & Schwartzi et al., 2015 [42] \\
\hline ccRCC stages (I and II vs. III and IV) & $\begin{array}{c}\text { SVM, random forests, SMO, naïve } \\
\text { Bayes, J48 on RNA-seq data } \\
\text { from TCGA }\end{array}$ & $\begin{array}{c}64 \text { and } 38 \text { genes selected. SVM was } \\
\text { the best predictor: sensitivity } 73.44 \% \text {, } \\
\text { specificity } 71.43 \% \text {, accuracy } 72.64 \% \text {, } \\
0.81 \text { ROC (on validation data) }\end{array}$ & Bhalla et al., 2017 [30] \\
\hline Papillary RCC stages & $\begin{array}{l}\text { KNN, SVM, naïve Bayes, random } \\
\text { forests, shrunken centroid }\end{array}$ & $\begin{array}{c}104 \text { selected genes. Shrunken was the } \\
\text { best predictor: PR-AUC 0.81, MCC } \\
0.71 \text {, accuracy } 88.5 \% \text { (in an } \\
\text { independent dataset) }\end{array}$ & Singh et al., 2018 [27] \\
\hline ccRCC survival & Lasso regression on TCGA data & $\begin{array}{l}4 \text { gene methylation data. According to } \\
\text { ROC curve: } 1 \text {-year survival rates } \\
0.794 \text {, 3-year } 0.752,5 \text {-year } 0.731\end{array}$ & Tang et al., 2020 [40] \\
\hline ccRCC stages (I, II and III, IV) & $\begin{array}{l}\text { SVM, logistic regression, MLP, } \\
\text { random forests and naïve Bayes } \\
\text { on TCGA data }\end{array}$ & $\begin{array}{l}23 \text { genes selected. SVM was the best } \\
\text { predictor: accuracy } 81.15 \% \text {, AUC } 0.86 \\
\text { (in a testing set) }\end{array}$ & Li et al., 2020 [32] \\
\hline Papillary RCC stages & $\begin{array}{l}\text { Random forests, naïve Bayes, } \\
\text { linear-SVM, KNN, shrunken } \\
\text { centroid, group Lasso, BEMKL on } \\
\text { TCGA data }\end{array}$ & $\begin{array}{l}\text { DNA methylation in addition to } \\
\text { previously selected [27] } 104 \text { features. } \\
\text { Random forests and group Lasso (for } \\
\text { both MCC 0.77, PR-AUC 0.79, } \\
\text { accuracy 90.4) }\end{array}$ & Singh et al., 2020 [28] \\
\hline
\end{tabular}

PCA: principal component analysis; AUC: area under the receiver operating curve; SVM: support vector machine; MLP: multi-layer perception; RF: random forest; KNN: k-nearest neighbor; auROC: area under the receiver operating characteristic curve; PR-AUC: maximum area under the precision recall curve; MCC: Matthews correlation coefficient; BEMKL: Bayesian efficient multiple kernel learning.

A study published in 2015 focused on prediction of kidney cancer survival ( $<$ or $\geq 5$ years) using TCGA RNA-seq data of 220 patients [42]. It was a complex study because the authors tested different datasets for training machine learning algorithms. In particular, both multimodal RNA-seq data (gene, exon, isoform and junction) and unimodal data (only gene, only exon, etc.) were used, and the results were compared by the area under the receiver operating curve (AUC). The support vector machine (SVM) and k-nearest neighbor (KNN) methods trained by multimodal data showed slightly better predictive accuracy (SVM_AUC $=0.6042$, KNN_AUC $=0.6444)$ in comparison to all unimodal datasets. Unfortunately, the sample size was small, and the total accuracy of the predictions resulted limited. Similarly to Jagga et al. [29], another study used RNA-seq expression data from a slightly higher number of ccRCC cases $(n=523)$ to train SVM, random forests, SMO, naïve Bayes and J48 algorithms [30]. The SVM reached a maximum accuracy of $72.64 \%$ and an ROC of 0.81 using 64 genes on the validation dataset (RCSP-set-Weka) and similar accuracy using 38 genes (RCSP-set-Weka-Hall). However, the performance improvements were limited compared to the previously cited article. In a recent study, ccRCC patients were classified in low- and high-risk categories based on methylation data of only four genes. In fact, using the Lasso regression, classification performances assessed on the testing group by the ROC curve were $0.794,0.752$ and 0.731 for the 1-, 3- and 5-year survival rates, respectively [40]. At the same time, using only 23 genes and the SVM algorithm, an accuracy of $81.15 \%$ and an AUC of 0.86 have been achieved [32].

In 2018 and 2020, the same authors dealt with papillary renal cell carcinoma (PRCC) to discriminate between early and late stages of the disease. In particular, 104 genes were selected from gene expression profiles derived from 161 patients and used in a shrunken 
classifier [27]. A test on an independent RNA-seq dataset showed a maximum area under the precision recall curve (PR-AUC) of 0.81, a Matthews correlation coefficient (MCC) of 0.71 and accuracy of $88.5 \%$. The integration of DNA methylation and gene expression data gave slightly better performance compared to the previous work [28].

A very recent study adopted different algorithms (SVM, decision tree, RF and ANN) to predict stages in ccRCC [43]. Unfortunately, large numbers of genes were used (12,897, 7251 and 6880), and the resulting performance was scarce.

We did not include two studies in Table 1 as they used learning methods only for variable selection $[33,39]$. Regarding these two studies, Li et al. developed a risk score model based on only 15 genes to predict the survival of patients with ccRCC who were subjected to surgery [33]. In particular, starting from gene expression data of $533 \mathrm{ccRCC}$ patients, discriminating genes were selected using the random forests algorithm. The results seem in line with those obtained in the previous studies; in fact, the risk score was significantly associated with overall survival (OS) and recurrence-free survival. Moreover, the risk score for the AUC was 0.78. Meanwhile, Zhang et al. selected four differentially expressed methylation-driven genes to construct a risk score prognostic model in ccRCC [39]. For the overall survival, the AUCs for 1,5 and 10 years were $0.734,0.717$ and 0.758 , respectively.

It is difficult to compare the performance of these different prediction algorithms, since they concern different RCC subtypes and each predictor is fed with different types and numbers of genes. Furthermore, among the prognosis predictors in ccRCC, some algorithms have been trained to predict survival, and others to distinguish early from late stages, which, although they are two strongly correlated variables, are not identical. It should be taken into account that the specific parameters used by programmers to implement each specific algorithm are not known in detail. However, the best performance was achieved in the most recent study on ccRCC prognosis (AUC 0.86) which also used the fewest genes, by employing an SVM that performed better than logistic regression, multi-layer perception (MLP), random forests and naïve Bayes.

\section{Commonly Selected Genes}

We performed features comparisons to identify which selected genes were in common among studies regarding ccRCC prognosis in Table 1 . Since genes can have synonymous names, we obtained their official names if these were not already adopted in the original papers, in order to obtain comparable gene lists. We identified few common genes: ATG13, HBG1 and HUS1B were the features shared among three studies, whereas CACNA1D, CASP9, CENPBD1, CTSG, EIF5B, EYA1, FABP7, FGFR3, GPR68, LINC01512, NFE2L3, RXRA, SLC22A16, SMIM3, SMLR1, TBX18, TMEM244, TNFSF4, TOB1 and UFSP2 were common between only two lists.

The HUS1B (Checkpoint protein HUS1B) gene forms a complex with Rad9 and Rad1 which are involved in response to damaged DNA, triggering cell cycle checkpoint signaling and DNA repair mechanisms [44]. CACNA1D (Voltage-dependent L-type calcium channel subunit alpha-1D) is lowly expressed in RCC [45], and the expression level of CASP9 (Caspase-9) is altered in RCC by rs12124078 SNP [46], while CTSG (Cathepsin G) inhibition enhances apoptosis in human renal carcinoma (Caki) cells [47]. The FABP7 (Fatty acidbinding protein, brain) gene is usually overexpressed in ccRCC compared to normal kidney, and its expression positively correlates with advanced clinical stage, poor survival and distant metastasis $[48,49]$. FGFR $3^{\circ}$ (fibroblast growth factor receptor 3 ) regulates cell proliferation, differentiation and apoptosis and it is frequently mutated in metastatic RCC [50] and downregulated in ccRCC [51]. High NFE2L3 (Nuclear factor erythroid 2-related factor 3) gene expression levels are associated with poor survival in ccRCC [52].

From this comparison, it emerges that different studies with the same goal, for example, prognosis prediction in ccRCC, selected different gene lists, but all their algorithms performed well. On the other hand, other studies with the specific purpose of selecting prognostic genes in ccRCC, which also used the TCGA source, obtained lists of genes that are different from each other and from the above-mentioned genes [53-56]. 
Despite joining all genes used by studies for ccRCC prognosis predictions, none of them were in common with the genes used for the papillary-type RCC predictions, confirming that the two cancer variants are very different at the molecular level.

\section{Comparisons with Non-Artificial Intelligence-Based Predictors}

We then analyzed the published studies which used non-AI-based predictors for diagnosis or prognosis in RCC to compare their performance with that of the predictors reported in Table 1. We selected some studies in which predictors were developed based on clustering or PCA of gene expression data. These studies, reported in Table 2, used microarray data, while studies reported in Table 1 used RNA-seq data.

Although these studies are not directly comparable to the above-mentioned ones because the AUC was not calculated, they generated lists of genes different from the above-mentioned studies but significantly associated with survival or tumor grade.

All studies demonstrated to have selected genes highly correlated to the overall survival, and one study reported a successful discrimination of patients from healthy individuals [57]. Regarding studies about ccRCC diagnosis, the genes CA9, FABP7, NDUFA4L2, PTHLH and SLC6A3 were common among the study using clustering/PCA (Table 2) and the one using learning algorithms (Table 1). Among these, FABP7 was already observed in the previously described analysis. CA9 (Carbonic anhydrase 9) and NDUFA4L2, a NADH dehydrogenase subunit, are strong candidate biomarkers for ccRCC metastasis [58-60]; moreover, NDUFA4L2 overexpression contributes to increase the drug resistance of ccRCC cells [61]. The overexpression of PTHLH (Parathyroid hormone-related protein) in ccRCC patients is associated with poor prognosis [62]. Further, SLC6A3 (Sodium-dependent dopamine transporter) is associated with ccRCC diagnosis and prognosis $[46,63]$.

Regarding studies about ccRCC prognosis, we joined the genes selected from these previous studies (reported in Table 2) with those selected more recently using advanced techniques (reported in Table 1) and then we compared these two lists. The common genes were F2RL1, FABP7, GPX3, HOXC10, ITGA2, LGALS2, LGALSL, MPZL2, NNMT, RGS1, S100A4, SLPI, SPINT2, TNFAIP6, UFSP2, VCAM1 and VEGFA.

Beside FABP7, the role of GPX3 (Glutathione peroxidase 3), NNMT (Nicotinamide N-methyltransferase), S100A4 (Protein S100-A4), SPINT2 (Kunitz-type protease inhibitor 2), TNFAIP6 (Tumor necrosis factor-inducible gene 6 protein), VCAM1 (vascular cell adhesion molecule 1) and VEGFA $^{\circ}$ (vascular endothelial growth factor A) is already known. In particular, the expression of GPX3 is decreased in cCRCC $[64,65]$. NNMT has been suggested as a diagnostic [66-68] and prognostic biomarker [69]. S100A4 could be a valid prognostic marker, since it is associated with ccRCC proliferation, migration and metastasis [70,71]. SPINT2 is lowly expressed in ccRCC and may act as a tumor suppressor gene, since its knockdown induces increased invasiveness, migration and bone metastasis [72-74]. TNFAIP6 mRNA expression is upregulated in ccRCC [75-77]. In addition, the expression of its protein (TSG-6) is upregulated in inflammatory states and by growth factors [78]. VCAM1 is upregulated in ccRCC and pRCC and downregulated in chromophobe RCC and oncocytoma [79]. It is also highly predictive for survival of patients with RCC [79]. VEGFA is a growth factor involved in angiogenesis, cell migration and apoptosis. This gene is upregulated in many tumors, including RCC, and its expression is correlated with tumor stage and progression [80]. It is targeted by miR-106a-5p, but expression of this microRNA is drastically decreased in ccRCC [81]. 
Table 2. The table collects the studies that used different techniques than machine learning to predict diagnosis and prognosis.

\begin{tabular}{|c|c|c|c|}
\hline Aim & Technique and Data & Results & Reference \\
\hline ccRCC survival at 5 years & $\begin{array}{l}\text { Clustering on cDNA microarray } \\
\text { (29 patients) }\end{array}$ & $\begin{array}{l}40 \text { genes correlated with survival (Kaplan-Meier, } \\
\qquad p<0.0001 \text { ) and histological grade. }\end{array}$ & Takahashi et al., 2001 [82] \\
\hline $\begin{array}{l}\text { metastatic ccRCC } \\
\text { subgroups }\end{array}$ & $\begin{array}{l}\text { Clustering on cDNA microarray } \\
\text { (58 patients) }\end{array}$ & $\begin{array}{l}45 \text { genes distinguishing groups for overall } \\
\text { survival }(p=0.001)\end{array}$ & Vasselli et al., 2003 [83] \\
\hline \multirow{2}{*}{$\begin{array}{l}\text { ccRCC survival } \\
\text { after surgery }\end{array}$} & \multirow{2}{*}{$\begin{array}{l}\text { Clustering and supervised PCA } \\
\text { on cDNA microarray } \\
\text { (177 patients) }\end{array}$} & $\begin{array}{c}259 \text { genes correlated with survival }(p<0.001 \text { by } \\
\text { the log-rank test on test set) }\end{array}$ & \multirow[t]{2}{*}{ Zhao et al., 2006 [84] } \\
\hline & & Top 4 genes correlated with survival $(p=0.02)$ & \\
\hline ccRCC vs. normal & \multirow{2}{*}{$\begin{array}{l}\text { Clustering and PCA on cDNA } \\
\text { microarray (16 patients) }\end{array}$} & $\begin{array}{l}21 \text { genes over expressed in ccRCC compared to } \\
\text { normal tissues }\end{array}$ & \multirow{2}{*}{ Skubitz et al., 2006 [57] } \\
\hline ccRCC subgroups & & $\begin{array}{l}\text { Fewer genes distinguishing } 2 \text { ccRCC subgroups } \\
\text { likely related to pathologic grade }\end{array}$ & \\
\hline ccRCC survival & $\begin{array}{l}\text { PCA and clustering and logical } \\
\text { analysis on cDNA microarray } \\
\text { (48 patients) }\end{array}$ & $\begin{array}{l}110 \text { genes associated with tumor stage }(p=0.009) \\
\text { and grade }(p=0.0007) \text { and survival (median } \\
\text { survival of } 8.6 \text { vs. } 2.0 \text { years, } p=0.002)\end{array}$ & Brannon et al., 2010 [85] \\
\hline
\end{tabular}

\section{Discussion}

The use of the patient's clinical and molecular variables is very useful for obtaining new information important for personalized therapy development. Today, we have much more molecular information available thanks to next-generation sequencing techniques and therefore more possibilities to identify the truly discriminating molecular features. There are several bioinformatic methods for the identification of discriminating variables, which subsequently will be used by the various artificial intelligence algorithms. These variables, such as transcripts, proteins or metabolites, could also represent new therapeutic targets.

Artificial intelligence systems are able to learn the relationships among data only by looking at the examples and are able to capture and reproduce non-linear relationships among the data. These algorithms are constantly being improved to ensure that they can learn better and faster and be more robust to the noise in the data. Another issue is that most machine learning algorithms are so-called "black boxes", that is, they derive an internal model of the functioning of reality, but this cannot be explained.

These machine learning methods can also stratify patients more accurately, identifying those who present a low-stage but high-risk expression profile tumor and therefore should receive adjuvant therapies and major attention. On the other hand, patients with a highstage but low-risk expression profile could receive less aggressive treatments under close observation. However, these objectives remain challenging, especially when considering the great molecular heterogeneity of kidney tumors.

In this study, firstly, we show that artificial intelligence algorithms yield fairly accurate predictions, even with a low number of variables (Table 1), but there is still a need to continue efforts to improve predictions. Secondly, among studies pursuing the same aim and starting from the same data (TCGA), good performance is obtained despite only a few discriminating variables being common. This may be due to the employment of different algorithms for the feature selection and the fact there are groups of genes with very similar expression profiles for which different algorithms choose different genes to represent the same class. Third, the comparison between AI- and non-AI-based predictors was not possible since different parameters are used to describe performance. For the same reason, the comparison with nomograms is not possible when the C-index is provided $[5,86,87]$ but only when the AUC is present. In this case, a nomogram reached an AUC of 0.813 and 0.799 for the 3-year and 5-year survival, respectively [7]. Similar performance (0.801 AUC) is obtained by integrating expression data in predicting a high ISUP (International Society of Urological Pathology) grade of ccRCC [88]. These results, obtained with very simple and transparent systems, are similar to or slightly lower than those of AI systems. 
In colon and breast cancers, AI predictors reached an accuracy of 0.767 and 0.807 , respectively, for disease recurrence [89]. Better results were obtained in the prediction of survival at 1 year and 5 years in esophageal carcinoma (0.883 and 0.884 AUC) [90]. Therefore, in other cancers, the results of the predictions are similar to those obtained for RCC.

To increase the accuracy of predictions in prognosis, data on mutations have been integrated with those of gene expression [91-93]. However, it is difficult to train an expert system to consider the mutation load of a sample since the effect of a mutation depends on the function of the gene and its position along the gene [94]. Unfortunately, since there is no such detailed information, all mutations are grouped together, and this diminishes the predictive power of expert systems.

In the future, thanks to the greater availability of data in TCGA, it will be possible to realize gender-, ethnic- and RCC variant-specific predictors.

\section{Conclusions}

AI-based predictors are powerful tools that can be continuously trained as new data become available. In this review, we summarized recent studies that adopted these predictors for diagnosis and prognosis in RCC. We show the good performances obtained so far, but also the need for improvement in order to achieve real clinical usefulness.

Author Contributions: Conceptualization, F.P.; investigation, M.G., M.C., B.S., A.S.; writingoriginal draft preparation, F.P., M.G.; writing-review and editing, M.S., A.C.; supervision, R.M. All authors have read and agreed to the published version of the manuscript.

Funding: This research received no external funding.

Conflicts of Interest: The authors declare no conflict of interest.

\section{References}

1. Moch, H.; Cubilla, A.L.; Humphrey, P.A.; Reuter, V.E.; Ulbright, T.M. The 2016 WHO Classification of Tumours of the Urinary System and Male Genital Organs-Part A: Renal, Penile, and Testicular Tumours. Eur. Urol. 2016, 70, 93-105. [CrossRef] [PubMed]

2. Santoni, M.; Conti, A.; Piva, F; Massari, F.; Ciccarese, C.; Burattini, L.; Cheng, L.; Lopez-Beltran, A.; Scarpelli, M.; Santini, D.; et al. Role of STAT3 pathway in genitourinary tumors. Future Sci. OA 2015, 1, FSO15. [CrossRef] [PubMed]

3. Sun, M.; Shariat, S.F.; Cheng, C.; Ficarra, V.; Murai, M.; Oudard, S.; Pantuck, A.J.; Zigeuner, R.; Karakiewicz, P.I. Prognostic factors and predictive models in renal cell carcinoma: A contemporary review. Eur. Urol. 2011, 60, 644-661. [CrossRef] [PubMed]

4. Volpe, A.; Patard, J.J. Prognostic factors in renal cell carcinoma. World J. Urol. 2010, 28, 319-327. [CrossRef]

5. Zhang, G.; Wu, Y.; Zhang, J.; Fang, Z.; Liu, Z.; Xu, Z.; Fan, Y. Nomograms for predicting long-term overall survival and disease-specific survival of patients with clear cell renal cell carcinoma. Onco. Targ. Ther. 2018, 11, 5535-5544. [CrossRef]

6. Zheng, W.; Zhu, W.; Yu, S.; Li, K.; Ding, Y.; Wu, Q.; Tang, Q.; Zhao, Q.; Lu, C.; Guo, C. Development and validation of a nomogram to predict overall survival for patients with metastatic renal cell carcinoma. BMC Cancer 2020, 20, 1066. [CrossRef]

7. Xia, M.; Yang, H.; Wang, Y.; Yin, K.; Bian, X.; Chen, J.; Shuang, W. Development and Validation of a Nomogram Predicting the Prognosis of Renal Cell Carcinoma After Nephrectomy. Cancer Manag. Res. 2020, 12, 4461-4473. [CrossRef]

8. Kamps, R.; Brandao, R.D.; Bosch, B.J.; Paulussen, A.D.; Xanthoulea, S.; Blok, M.J.; Romano, A. Next-Generation Sequencing in Oncology: Genetic Diagnosis, Risk Prediction and Cancer Classification. Int. J. Mol. Sci. 2017, 18, 308. [CrossRef]

9. Rahman, M.M.; Usman, O.L.; Muniyandi, R.C.; Sahran, S.; Mohamed, S.; Razak, R.A. A Review of Machine Learning Methods of Feature Selection and Classification for Autism Spectrum Disorder. Brain Sci. 2020, 10, 949. [CrossRef]

10. Shah, M.; Naik, N.; Somani, B.K.; Hameed, B.M.Z. Artificial intelligence (AI) in urology-Current use and future directions: An iTRUE study. Turk. J. Urol. 2020, 46, S27-S39. [CrossRef]

11. Pai, R.K.; Van Booven, D.J.; Parmar, M.; Lokeshwar, S.D.; Shah, K.; Ramasamy, R.; Arora, H. A review of current advancements and limitations of artificial intelligence in genitourinary cancers. Am. J. Clin. Exp. Urol. 2020, 8, 152-162. [PubMed]

12. Hamamoto, R.; Suvarna, K.; Yamada, M.; Kobayashi, K.; Shinkai, N.; Miyake, M.; Takahashi, M.; Jinnai, S.; Shimoyama, R.; Sakai, A.; et al. Application of Artificial Intelligence Technology in Oncology: Towards the Establishment of Precision Medicine. Cancers 2020, 12, 3532. [CrossRef] [PubMed]

13. Hamet, P.; Tremblay, J. Artificial intelligence in medicine. Metabolism 2017, 69S, S36-S40. [CrossRef] [PubMed]

14. Anagnostou, T.; Remzi, M.; Lykourinas, M.; Djavan, B. Artificial neural networks for decision-making in urologic oncology. Eur. Urol. 2003, 43, 596-603. [CrossRef]

15. Bhandari, A.; Ibrahim, M.; Sharma, C.; Liong, R.; Gustafson, S.; Prior, M. CT-based radiomics for differentiating renal tumours: A systematic review. Abdom. Radiol. 2020. [CrossRef] [PubMed] 
16. Piva, F.; Tartari, F.; Giulietti, M.; Aiello, M.M.; Cheng, L.; Lopez-Beltran, A.; Mazzucchelli, R.; Cimadamore, A.; Cerqueti, R.; Battelli, N.; et al. Predicting future cancer burden in the United States by artificial neural networks. Future Oncol. 2020. [CrossRef]

17. Santoni, M.; Piva, F.; Porta, C.; Bracarda, S.; Heng, D.Y.; Matrana, M.R.; Grande, E.; Mollica, V.; Aurilio, G.; Rizzo, M.; et al. Artificial Neural Networks as a Way to Predict Future Kidney Cancer Incidence in the United States. Clin. Genitourin. Cancer 2020. [CrossRef]

18. Hugle, M.; Omoumi, P.; van Laar, J.M.; Boedecker, J.; Hugle, T. Applied machine learning and artificial intelligence in rheumatology. Rheumatol. Adv. Pract. 2020, 4, rkaa005. [CrossRef]

19. Farris, A.B.; Vizcarra, J.; Amgad, M.; Cooper, L.A.D.; Gutman, D.; Hogan, J. Artificial Intelligence and Algorithmic Computational Pathology: Introduction with Renal Allograft Examples. Histopathology 2020. [CrossRef]

20. Dana, J.; Agnus, V.; Ouhmich, F.; Gallix, B. Multimodality Imaging and Artificial Intelligence for Tumor Characterization: Current Status and Future Perspective. Semin. Nucl. Med. 2020, 50, 541-548. [CrossRef]

21. Supriya, M.; Deepa, A.J. A novel approach for breast cancer prediction using optimized ANN classifier based on big data environment. Health Care Manag. Sci. 2020, 23, 414-426. [CrossRef] [PubMed]

22. Huang, M.W.; Chen, C.W.; Lin, W.C.; Ke, S.W.; Tsai, C.F. SVM and SVM Ensembles in Breast Cancer Prediction. PLoS ONE 2017, 12, e0161501. [CrossRef] [PubMed]

23. Wongvibulsin, S.; Wu, K.C.; Zeger, S.L. Clinical risk prediction with random forests for survival, longitudinal, and multivariate (RF-SLAM) data analysis. BMC Med. Res. Methodol. 2019, 20, 1. [CrossRef] [PubMed]

24. Raita, Y.; Goto, T.; Faridi, M.K.; Brown, D.F.M.; Camargo, C.A., Jr.; Hasegawa, K. Emergency department triage prediction of clinical outcomes using machine learning models. Crit. Care 2019, 23, 64. [CrossRef]

25. Shu, J.; Wen, D.; Xi, Y.; Xia, Y.; Cai, Z.; Xu, W.; Meng, X.; Liu, B.; Yin, H. Clear cell renal cell carcinoma: Machine learning-based computed tomography radiomics analysis for the prediction of WHO/ISUP grade. Eur. J. Radiol. 2019, 121, 108738. [CrossRef]

26. Rudin, C. Stop explaining black box machine learning models for high stakes decisions and use interpretable models instead. Nat. Mach. Intell. 2019, 1, 206-215. [CrossRef]

27. Singh, N.P.; Bapi, R.S.; Vinod, P.K. Machine learning models to predict the progression from early to late stages of papillary renal cell carcinoma. Comput. Biol. Med. 2018, 100, 92-99. [CrossRef]

28. Singh, N.P.; Vinod, P.K. Integrative analysis of DNA methylation and gene expression in papillary renal cell carcinoma. Mol. Gen. Genom. 2020, 295, 807-824. [CrossRef]

29. Jagga, Z.; Gupta, D. Classification models for clear cell renal carcinoma stage progression, based on tumor RNAseq expression trained supervised machine learning algorithms. BMC Proc. 2014, 8, S2. [CrossRef]

30. Bhalla, S.; Chaudhary, K.; Kumar, R.; Sehgal, M.; Kaur, H.; Sharma, S.; Raghava, G.P. Gene expression-based biomarkers for discriminating early and late stage of clear cell renal cancer. Sci. Rep. 2017, 7, 44997. [CrossRef]

31. Rahman, M.; Jackson, L.K.; Johnson, W.E.; Li, D.Y.; Bild, A.H.; Piccolo, S.R. Alternative preprocessing of RNA-Sequencing data in The Cancer Genome Atlas leads to improved analysis results. Bioinformatics 2015, 31, 3666-3672. [CrossRef] [PubMed]

32. Li, F.; Yang, M.; Li, Y.; Zhang, M.; Wang, W.; Yuan, D.; Tang, D. An improved clear cell renal cell carcinoma stage prediction model based on gene sets. BMC Bioinf. 2020, 21, 232. [CrossRef] [PubMed]

33. Li, P.; Ren, H.; Zhang, Y.; Zhou, Z. Fifteen-gene expression based model predicts the survival of clear cell renal cell carcinoma. Medicine 2018, 97, e11839. [CrossRef] [PubMed]

34. Rehrauer, H.; Opitz, L.; Tan, G.; Sieverling, L.; Schlapbach, R. Blind spots of quantitative RNA-seq: The limits for assessing abundance, differential expression, and isoform switching. BMC Bioinf. 2013, 14, 370. [CrossRef]

35. Ozsolak, F.; Milos, P.M. RNA sequencing: Advances, challenges and opportunities. Nat. Rev. Gen. 2011, 12, 87-98. [CrossRef]

36. Hirsch, C.D.; Springer, N.M.; Hirsch, C.N. Genomic limitations to RNA sequencing expression profiling. Plant J. 2015, 84, 491-503. [CrossRef]

37. Lenzi, L.; Facchin, F.; Piva, F.; Giulietti, M.; Pelleri, M.C.; Frabetti, F.; Vitale, L.; Casadei, R.; Canaider, S.; Bortoluzzi, S.; et al. TRAM (Transcriptome Mapper): Database-driven creation and analysis of transcriptome maps from multiple sources. BMC Genom. 2011, 12, 121. [CrossRef]

38. Yang, W.; Yoshigoe, K.; Qin, X.; Liu, J.S.; Yang, J.Y.; Niemierko, A.; Deng, Y.; Liu, Y.; Dunker, A.; Chen, Z.; et al. Identification of genes and pathways involved in kidney renal clear cell carcinoma. BMC Bioinf. 2014, 15, S2. [CrossRef]

39. Zhang, D.; Wang, Y.; Hu, X. Identification and Comprehensive Validation of a DNA Methylation-Driven Gene-Based Prognostic Model for Clear Cell Renal Cell Carcinoma. DNA Cell Biol. 2020, 39, 1799-1812. [CrossRef]

40. Tang, W.; Cao, Y.; Ma, X. Novel prognostic prediction model constructed through machine learning on the basis of methylationdriven genes in kidney renal clear cell carcinoma. Biosci. Rep. 2020, 40. [CrossRef]

41. Vidal, M.; Cusick, M.E.; Barabasi, A.L. Interactome networks and human disease. Cell 2011, 144, 986-998. [CrossRef] [PubMed]

42. Schwartzi, M.; Parkl, M.; Phanl, J.H.; Wang, M.D. Integration of multimodal RNA-seq data for prediction of kidney cancer survival In Proceedings of the IEEE International Conference Bioinformatics and Biomedicine, Washington, DC, USA, 9-12 November 2015; Volume 2015, pp. 1591-1595. [CrossRef]

43. Kweon, S.; Lee, J.H.; Lee, Y.; Park, Y.R. Personal Health Information Inference Using Machine Learning on RNA Expression Data from Patients With Cancer: Algorithm Validation Study. J. Med. Internet Res. 2020, 22, e18387. [CrossRef] [PubMed]

44. Lyndaker, A.M.; Vasileva, A.; Wolgemuth, D.J.; Weiss, R.S.; Lieberman, H.B. Clamping down on mammalian meiosis. Cell Cycle 2013, 12, 3135-3145. [CrossRef] [PubMed] 
45. Phan, N.N.; Wang, C.Y.; Chen, C.F.; Sun, Z.; Lai, M.D.; Lin, Y.C. Voltage-gated calcium channels: Novel targets for cancer therapy. Oncol. Lett. 2017, 14, 2059-2074. [CrossRef] [PubMed]

46. Purdue, M.P.; Song, L.; Scelo, G.; Houlston, R.S.; Wu, X.; Sakoda, L.C.; Thai, K.; Graff, R.E.; Rothman, N.; Brennan, P.; et al. Pathway Analysis of Renal Cell Carcinoma Genome-Wide Association Studies Identifies Novel Associations. Cancer Epidemiol. Biomarkers Prev. 2020, 29, 2065-2069. [CrossRef] [PubMed]

47. Woo, S.M.; Min, K.J.; Seo, S.U.; Kim, S.; Park, J.W.; Song, D.K.; Lee, H.S.; Kim, S.H.; Kwon, T.K. Up-regulation of 5-lipoxygenase by inhibition of cathepsin G enhances TRAIL-induced apoptosis through down-regulation of survivin. Oncotarget 2017, 8 , 106672-106684. [CrossRef]

48. Zhou, J.; Deng, Z.; Chen, Y.; Gao, Y.; Wu, D.; Zhu, G.; Li, L.; Song, W.; Wang, X.; Wu, K.; et al. Overexpression of FABP7 promotes cell growth and predicts poor prognosis of clear cell renal cell carcinoma. Urol. Oncol. 2015, 33, 113.e9-113.e17. [CrossRef]

49. Nagao, K.; Shinohara, N.; Smit, F.; de Weijert, M.; Jannink, S.; Owada, Y.; Mulders, P.; Oosterwijk, E.; Matsuyama, H. Fatty acid binding protein 7 may be a marker and therapeutic targets in clear cell renal cell carcinoma. BMC Cancer 2018, 18, 1114. [CrossRef]

50. Fiorentino, M.; Gruppioni, E.; Massari, F.; Giunchi, F.; Altimari, A.; Ciccarese, C.; Bimbatti, D.; Scarpa, A.; Iacovelli, R.; Porta, C.; et al. Wide spetcrum mutational analysis of metastatic renal cell cancer: A retrospective next generation sequencing approach. Oncotarget 2017, 8, 7328-7335. [CrossRef]

51. Behbahani, T.E.; Thierse, C.; Baumann, C.; Holl, D.; Bastian, P.J.; von Ruecker, A.; Muller, S.C.; Ellinger, J.; Hauser, S. Tyrosine kinase expression profile in clear cell renal cell carcinoma. World J. Urol. 2012, 30, 559-565. [CrossRef]

52. Wang, J.; Zhao, H.; Dong, H.; Zhu, L.; Wang, S.; Wang, P.; Ren, Q.; Zhu, H.; Chen, J.; Lin, Z.; et al. LAT, HOXD3 and NFE2L3 identified as novel DNA methylation-driven genes and prognostic markers in human clear cell renal cell carcinoma by integrative bioinformatics approaches. J. Cancer 2019, 10, 6726-6737. [CrossRef] [PubMed]

53. Gu, Y.; Lu, L.; Wu, L.; Chen, H.; Zhu, W.; He, Y. Identification of prognostic genes in kidney renal clear cell carcinoma by RNAseq data analysis. Mol. Med. Rep. 2017, 15, 1661-1667. [CrossRef] [PubMed]

54. Wu, J.; Jin, S.; Gu, W.; Wan, F.; Zhang, H.; Shi, G.; Qu, Y.; Ye, D. Construction and Validation of a 9-Gene Signature for Predicting Prognosis in Stage III Clear Cell Renal Cell Carcinoma. Front. Oncol. 2019, 9, 152. [CrossRef] [PubMed]

55. Berglund, A.; Amankwah, E.K.; Kim, Y.C.; Spiess, P.E.; Sexton, W.J.; Manley, B.; Park, H.Y.; Wang, L.; Chahoud, J.; Chakrabarti, R.; et al. Influence of gene expression on survival of clear cell renal cell carcinoma. Cancer Med. 2020, 9, 8662-8675. [CrossRef] [PubMed]

56. Li, F.; Hu, W.F.; Zhang, W.; Li, G.H.; Guo, Y.L. A 17-Gene Signature Predicted Prognosis in Renal Cell Carcinoma. Dis. Markers 2020, 2020. [CrossRef]

57. Skubitz, K.M.; Zimmermann, W.; Kammerer, R.; Pambuccian, S.; Skubitz, A.P. Differential gene expression identifies subgroups of renal cell carcinoma. J. Lab. Clin. Med. 2006, 147, 250-267. [CrossRef]

58. Apanovich, N.; Peters, M.; Apanovich, P.; Mansorunov, D.; Markova, A.; Matveev, V.; Karpukhin, A. The Genes-Candidates for Prognostic Markers of Metastasis by Expression Level in Clear Cell Renal Cell Cancer. Diagnostics 2020, 10, 30. [CrossRef]

59. Wang, L.; Peng, Z.; Wang, K.; Qi, Y.; Yang, Y.; Zhang, Y.; An, X.; Luo, S.; Zheng, J. NDUFA4L2 is associated with clear cell renal cell carcinoma malignancy and is regulated by ELK1. PeerJ 2017, 5, e4065. [CrossRef]

60. Liu, L.; Lan, G.; Peng, L.; Xie, X.; Peng, F.; Yu, S.; Wang, Y.; Tang, X. NDUFA4L2 expression predicts poor prognosis in clear cell renal cell carcinoma patients. Ren. Fail. 2016, 38, 1199-1205. [CrossRef]

61. Lucarelli, G.; Rutigliano, M.; Sallustio, F.; Ribatti, D.; Giglio, A.; Lepore Signorile, M.; Grossi, V.; Sanese, P.; Napoli, A.; Maiorano, E.; et al. Integrated multi-omics characterization reveals a distinctive metabolic signature and the role of NDUFA4L2 in promoting angiogenesis, chemoresistance, and mitochondrial dysfunction in clear cell renal cell carcinoma. Aging 2018, 10, 3957-3985. [CrossRef]

62. Yao, M.; Murakami, T.; Shioi, K.; Mizuno, N.; Ito, H.; Kondo, K.; Hasumi, H.; Sano, F.; Makiyama, K.; Nakaigawa, N.; et al. Tumor signatures of PTHLH overexpression, high serum calcium, and poor prognosis were observed exclusively in clear cell but not non clear cell renal carcinomas. Cancer Med. 2014, 3, 845-854. [CrossRef] [PubMed]

63. Hansson, J.; Lindgren, D.; Nilsson, H.; Johansson, E.; Johansson, M.; Gustavsson, L.; Axelson, H. Overexpression of Functional SLC6A3 in Clear Cell Renal Cell Carcinoma. Clin. Cancer Res. 2017, 23, 2105-2115. [CrossRef] [PubMed]

64. Rudenko, E.; Kondratov, O.; Gerashchenko, G.; Lapska, Y.; Kravchenko, S.; Koliada, O.; Vozianov, S.; Zgonnyk, Y.; Kashuba, V. Aberrant expression of selenium-containing glutathione peroxidases in clear cell renal cell carcinomas. Exp. Oncol. 2015, 37, 105-110. [CrossRef]

65. Liu, Q.; Jin, J.; Ying, J.; Sun, M.; Cui, Y.; Zhang, L.; Xu, B.; Fan, Y.; Zhang, Q. Frequent epigenetic suppression of tumor suppressor gene glutathione peroxidase 3 by promoter hypermethylation and its clinical implication in clear cell renal cell carcinoma. Int. J. Mol. Sci. 2015, 16, 10636-10649. [CrossRef]

66. Kim, D.S.; Choi, Y.P.; Kang, S.; Gao, M.Q.; Kim, B.; Park, H.R.; Choi, Y.D.; Lim, J.B.; Na, H.J.; Kim, H.K.; et al. Panel of candidate biomarkers for renal cell carcinoma. J. Proteome Res. 2010, 9, 3710-3719. [CrossRef]

67. Su Kim, D.; Choi, Y.D.; Moon, M.; Kang, S.; Lim, J.B.; Kim, K.M.; Park, K.M.; Cho, N.H. Composite three-marker assay for early detection of kidney cancer. Cancer Epidemiol. Biomarkers Prev. 2013, 22, 390-398. [CrossRef]

68. Kim, D.S.; Ham, W.S.; Jang, W.S.; Cho, K.S.; Choi, Y.D.; Kang, S.; Kim, B.; Kim, K.J.; Lim, E.J.; Rha, S.Y.; et al. Scale-Up Evaluation of a Composite Tumor Marker Assay for the Early Detection of Renal Cell Carcinoma. Diagnostics 2020, 10, 750. [CrossRef] 
69. Neely, B.A.; Wilkins, C.E.; Marlow, L.A.; Malyarenko, D.; Kim, Y.; Ignatchenko, A.; Sasinowska, H.; Sasinowski, M.; Nyalwidhe, J.O.; Kislinger, T.; et al. Proteotranscriptomic Analysis Reveals Stage Specific Changes in the Molecular Landscape of Clear-Cell Renal Cell Carcinoma. PLoS ONE 2016, 11, e0154074. [CrossRef]

70. Yang, H.; Zhao, K.; Yu, Q.; Wang, X.; Song, Y.; Li, R. Evaluation of plasma and tissue S100A4 protein and mRNA levels as potential markers of metastasis and prognosis in clear cell renal cell carcinoma. J. Int. Med. Res. 2012, 40, 475-485. [CrossRef]

71. Kuper, C.; Beck, F.X.; Neuhofer, W. NFAT5-mediated expression of S100A4 contributes to proliferation and migration of renal carcinoma cells. Front. Physiol. 2014, 5, 293. [CrossRef]

72. Yamauchi, M.; Kataoka, H.; Itoh, H.; Seguchi, T.; Hasui, Y.; Osada, Y. Hepatocyte growth factor activator inhibitor types 1 and 2 are expressed by tubular epithelium in kidney and down-regulated in renal cell carcinoma. J. Urol. 2004, 171, 890-896. [CrossRef]

73. Morris, M.R.; Gentle, D.; Abdulrahman, M.; Maina, E.N.; Gupta, K.; Banks, R.E.; Wiesener, M.S.; Kishida, T.; Yao, M.; Teh, B.; et al. Tumor suppressor activity and epigenetic inactivation of hepatocyte growth factor activator inhibitor type 2/SPINT2 in papillary and clear cell renal cell carcinoma. Cancer Res. 2005, 65, 4598-4606. [CrossRef]

74. Yamasaki, K.; Mukai, S.; Sugie, S.; Nagai, T.; Nakahara, K.; Kamibeppu, T.; Sakamoto, H.; Shibasaki, N.; Terada, N.; Toda, Y.; et al. Dysregulated HAI-2 Plays an Important Role in Renal Cell Carcinoma Bone Metastasis through Ligand-Dependent MET Phosphorylation. Cancers 2018, 10, 190. [CrossRef]

75. Schrodter, S.; Braun, M.; Syring, I.; Klumper, N.; Deng, M.; Schmidt, D.; Perner, S.; Muller, S.C.; Ellinger, J. Identification of the dopamine transporter SLC6A3 as a biomarker for patients with renal cell carcinoma. Mol. Cancer 2016, 15, 10. [CrossRef]

76. Gu, Y.; Zou, Y.M.; Lei, D.; Huang, Y.; Li, W.; Mo, Z.; Hu, Y. Promoter DNA methylation analysis reveals a novel diagnostic CpG-based biomarker and RAB25 hypermethylation in clear cell renel cell carcinoma. Sci. Rep. 2017, 7, 14200. [CrossRef]

77. Tian, Z.H.; Yuan, C.; Yang, K.; Gao, X.L. Systematic identification of key genes and pathways in clear cell renal cell carcinoma on bioinformatics analysis. Ann. Transl. Med. 2019, 7, 89. [CrossRef]

78. Milner, C.M.; Day, A.J. TSG-6: A multifunctional protein associated with inflammation. J. Cell Sci. 2003, 116, 1863-1873. [CrossRef]

79. Shioi, K.; Komiya, A.; Hattori, K.; Huang, Y.; Sano, F.; Murakami, T.; Nakaigawa, N.; Kishida, T.; Kubota, Y.; Nagashima, Y.; et al. Vascular cell adhesion molecule 1 predicts cancer-free survival in clear cell renal carcinoma patients. Clin. Cancer Res. 2006, 12, 7339-7346. [CrossRef]

80. Albiges, L.; Salem, M.; Rini, B.; Escudier, B. Vascular endothelial growth factor-targeted therapies in advanced renal cell carcinoma. Hematol. Oncol. Clin. North Am. 2011, 25, 813-833. [CrossRef]

81. Ma, J.; Wang, W.; Azhati, B.; Wang, Y.; Tusong, H. miR-106a-5p Functions as a Tumor Suppressor by Targeting VEGFA in Renal Cell Carcinoma. Dis. Markers 2020, 2020, 8837941. [CrossRef]

82. Takahashi, M.; Rhodes, D.R.; Furge, K.A.; Kanayama, H.; Kagawa, S.; Haab, B.B.; Teh, B.T. Gene expression profiling of clear cell renal cell carcinoma: Gene identification and prognostic classification. Proc. Natl. Acad. Sci. USA 2001, 98, 9754-9759. [CrossRef] [PubMed]

83. Vasselli, J.R.; Shih, J.H.; Iyengar, S.R.; Maranchie, J.; Riss, J.; Worrell, R.; Torres-Cabala, C.; Tabios, R.; Mariotti, A.; Stearman, R.; et al. Predicting survival in patients with metastatic kidney cancer by gene-expression profiling in the primary tumor. Proc. Natl. Acad. Sci. USA 2003, 100, 6958-6963. [CrossRef] [PubMed]

84. Zhao, H.; Ljungberg, B.; Grankvist, K.; Rasmuson, T.; Tibshirani, R.; Brooks, J.D. Gene expression profiling predicts survival in conventional renal cell carcinoma. PLoS Med. 2006, 3, e13. [CrossRef]

85. Brannon, A.R.; Reddy, A.; Seiler, M.; Arreola, A.; Moore, D.T.; Pruthi, R.S.; Wallen, E.M.; Nielsen, M.E.; Liu, H.; Nathanson, K.L.; et al. Molecular Stratification of Clear Cell Renal Cell Carcinoma by Consensus Clustering Reveals Distinct Subtypes and Survival Patterns. Genes Cancer 2010, 1, 152-163. [CrossRef]

86. Yaycioglu, O.; Eskicorapci, S.; Karabulut, E.; Soyupak, B.; Gogus, C.; Divrik, T.; Turkeri, L.; Yazici, S.; Ozen, H. A preoperative prognostic model predicting recurrence-free survival for patients with kidney cancer. Jpn. J. Clin. Oncol. 2013, 43, 63-68. [CrossRef]

87. Raj, G.V.; Thompson, R.H.; Leibovich, B.C.; Blute, M.L.; Russo, P.; Kattan, M.W. Preoperative nomogram predicting 12-year probability of metastatic renal cancer. J. Urol. 2008, 179, 2146-2151; discussion 2151. [CrossRef]

88. Wu, J.; Xu, W.H.; Wei, Y.; Qu, Y.Y.; Zhang, H.L.; Ye, D.W. An Integrated Score and Nomogram Combining Clinical and Immunohistochemistry Factors to Predict High ISUP Grade Clear Cell Renal Cell Carcinoma. Front. Oncol. 2018, 8, 634. [CrossRef]

89. Park, C.; Ahn, J.; Kim, H.; Park, S. Integrative gene network construction to analyze cancer recurrence using semi-supervised learning. PLoS ONE 2014, 9, e86309. [CrossRef]

90. Sato, F.; Shimada, Y.; Selaru, F.M.; Shibata, D.; Maeda, M.; Watanabe, G.; Mori, Y.; Stass, S.A.; Imamura, M.; Meltzer, S.J. Prediction of survival in patients with esophageal carcinoma using artificial neural networks. Cancer 2005, 103, 1596-1605. [CrossRef]

91. Yu, J.; Hu, Y.; Xu, Y.; Wang, J.; Kuang, J.; Zhang, W.; Shao, J.; Guo, D.; Wang, Y. LUADpp: An effective prediction model on prognosis of lung adenocarcinomas based on somatic mutational features. BMC Cancer 2019, 19, 263. [CrossRef]

92. Baek, B.; Lee, H. Prediction of survival and recurrence in patients with pancreatic cancer by integrating multi-omics data. Sci. Rep. 2020, 10, 18951. [CrossRef]

93. Kim, D.; Li, R.; Dudek, S.M.; Wallace, J.R.; Ritchie, M.D. Binning somatic mutations based on biological knowledge for predicting survival: An application in renal cell carcinoma. Pac. Symp. Biocomput. 2015, 96-107.

94. Piva, F.; Giulietti, M.; Occhipinti, G.; Santoni, M.; Massari, F.; Sotte, V.; Iacovelli, R.; Burattini, L.; Santini, D.; Montironi, R.; et al Computational analysis of the mutations in BAP1, PBRM1 and SETD2 genes reveals the impaired molecular processes in renal cell carcinoma. Oncotarget 2015, 6, 32161-32168. [CrossRef] 